\title{
Article
}

\section{Using a High-Power Fibre Laser to Cut Concrete}

\author{
Kaori Nagai * and Kazuki Shimizu
}

check for

updates

Citation: Nagai, K.; Shimizu, K.

Using a High-Power Fibre Laser to

Cut Concrete. Appl. Sci. 2021, 11, 4414

https://doi.org/10.3390/app11104414

Received: 1 February 2021

Accepted: 8 May 2021

Published: 13 May 2021

Publisher's Note: MDPI stays neutral with regard to jurisdictional claims in published maps and institutional affiliations.

Copyright: (c) 2021 by the authors. Licensee MDPI, Basel, Switzerland. This article is an open access article distributed under the terms and conditions of the Creative Commons Attribution (CC BY) license (https:// creativecommons.org/licenses/by/ $4.0 /)$.
Department of Architecture and Architectural Engineering, College of Industrial Technology, Nihon University, Chiba 275-8575, Japan; cikz20017@g.nihon-u.ac.jp

* Correspondence: nagai.kaori@nihon-u.ac.jp

\begin{abstract}
Concrete cutting at construction sites causes problems such as noise, vibration, and dust. In particular, during the demolition and renovation work on buildings in urban areas, protection against noise, vibration, dust, etc., is needed. Concrete cutting using a $\mathrm{CO}_{2}$ laser was investigated 20 years ago. However, this method had never used because the equipment is difficult to carry. In this study, we used a portable fibre laser, which is convenient to carry. Two types of concretes with different strengths were prepared for the experiment. High-strength concrete has never been used in similar research before. High-strength concrete is just only used for skyscrapers because of its high quality and costs. Furthermore, it has already been used for skyscrapers in Japan. It is for this reason that we chose to use it in this study. Irradiation measurements were conducted under various conditions using laser powers of 6 and $9 \mathrm{~kW}$. It was confirmed that the cutting effectiveness of $\mathrm{CO}_{2}$ and fibre lasers was approximately identical for concretes with a thickness of $200 \mathrm{~mm}$. Furthermore, the cutting effectiveness for the two concretes with different densities was almost the same. However, the situation after cutting was different because the vitrification of the cutting and glass formation progressed in low-density concrete and an explosion phenomenon occurred in high-density concrete, simultaneously. This study suggests that laser concrete cutting can be used as a solution when noise and dust are major problems.
\end{abstract}

Keywords: laser; cutting; concrete; laser condition; cutting depth

\section{Introduction}

Studies on techniques for dismantling and cutting reinforced concrete structures have been conducted since the 1970s [1], typically using concrete cutters, concrete hammers, and similar tools [2]. However, these tools create noise, vibration, dust, and reaction forces. To date, many techniques have been developed to reduce noise and vibration, including wire sawing [3], wall sawing [4], and buster techniques. However, none of these techniques have been able to solve these problems [5].

Laser technology offers a comprehensive solution. However, this technology has not been used because of issues such as the cost, size, and weight of the equipment. In recent years, the output power and efficiency of laser equipment have increased and the price has dropped [6]. Therefore, we believe that this technology has a promising future. The benefits of laser technology include its low noise, vibration, and dust, as well as its no reaction force [7]. Therefore, the introduction of lasers to construction sites will contribute to a better working environment owing to their low noise and cause less burden on the operator, owing to their minimal reaction force [8].

Laser cutting has been practiced in the construction field since 1986 [9-14]. In 1994, a $\mathrm{CO}_{2}$ laser was proven to have the ability to cut to a depth of approximately $300 \mathrm{~mm}$ with an output power of $9 \mathrm{~kW}$ and a cutting speed of $0.4 \mathrm{~cm} / \mathrm{min}$ [13]. However, this method has not been adopted because the equipment is difficult to carry. In this study, we have used a portable fibre laser, which is convenient to carry. 
Furthermore, the author has been studying the use of lasers in the construction field $[8,14-16]$. We have shown that these results confirmed that, the level of effectiveness differs depending on different heat volumes, even if the materials are the same.

Thus, a variety of factors, including the laser power, cutting speed, composition, and thickness of the object, are significant. According to this background, we focused on two types of concretes, including high-strength concrete, which has been used for skyscrapers. These results suggest cutting concrete to reconstruct include skyscrapers.

Other issues to be considered include using laser oscillators, miniaturising the power supply and other equipment, improving the handling performance of beam delivery, establishing safety measures, and cost. Therefore, although lasers can cut concrete, many issues need to be addressed to make them practically applicable.

In this study, the cutting effectiveness of a fibre laser is examined. Specifically, the effects of cutting and additional issues that arise under two different concrete strengths and two different laser conditions for a cutting depth for $200 \mathrm{~mm}$ thick concrete are discussed.

\section{Materials and Experiment Procedure}

\subsection{Materials}

The concrete formulations used for the test specimens are listed in Table 1. Two types of test specimens were used: concrete for general buildings with a strength of $20 \mathrm{~N} / \mathrm{mm}^{2}$ and high-strength concrete with a strength of $130 \mathrm{~N} / \mathrm{mm}^{2}$.

Table 1. Mix proportion.

\begin{tabular}{ccc}
\hline Concrete & Ordinary & High-Strength \\
\hline Strength $\left(\mathrm{N} / \mathrm{mm}^{2}\right)$ & 20 & 130 \\
Slump $(\mathrm{cm})$ & 18 & 65 \\
Air content $(\%)$ & 4.5 & 2.0 \\
Water-cement ratio $(\%)$ & 63.3 & 14.0 \\
Sand-aggregate ratio $(\%)$ & 50.7 & 31.0 \\
\hline
\end{tabular}

The test specimens were prepared with a concrete cutter using a $100 \mathrm{~mm} \times 100 \mathrm{~mm} \times$ $400 \mathrm{~mm}$ concrete mould and then sealed for 92 weeks. The dimensions of the test specimens were $100 \mathrm{~mm} \times 50 \mathrm{~mm} \times 200 \mathrm{~mm}$.

Table 2 lists the laser irradiation conditions. The irradiation conditions represented a combination of two levels of laser power and five levels of cutting speed. Laser irradiation was performed twice under each condition.

Table 2. Laser irradiation conditions.

\begin{tabular}{cc} 
Laser output $(\mathrm{kW})$ & 6,9 \\
Fibre core diameter $(\mu \mathrm{m})$ & 100 \\
Cutting speed $(\mathrm{mm} / \mathrm{min})$ & $20,40,60,80,100$ \\
Gas type & Air \\
Gas pressure $(\mathrm{MPa})$ & 0.95 \\
DFS distance $(\mathrm{mm})$ & 0 \\
\hline
\end{tabular}

\subsection{Laser Oscillator}

A $12 \mathrm{~kW} \mathrm{CW} \mathrm{fibre} \mathrm{laser} \mathrm{was} \mathrm{used} \mathrm{as} \mathrm{the} \mathrm{laser} \mathrm{oscillator.} \mathrm{The} \mathrm{power} \mathrm{range} \mathrm{was} \mathrm{between}$ 6 and $9 \mathrm{~kW}$ with focal irradiation. Air was used as the assist gas and sprayed at an angle of approximately $75^{\circ}$ to the irradiated surface.

\subsection{Method}

A schematic of the laser irradiation is shown in Figure 1. In the experiment, each concrete test specimen was irradiated with a laser in the downward direction under pre-set irradiation conditions. 

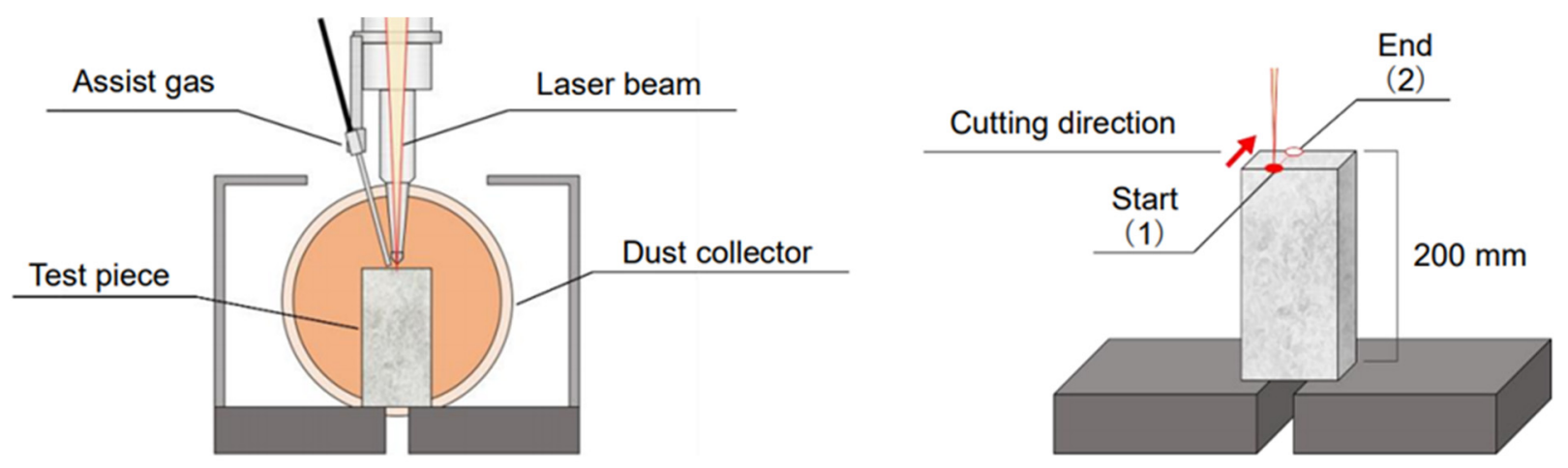

Figure 1. Schematic of laser irradiation.

\subsection{Evaluation Method}

\subsubsection{Measuring the Cutting Depth}

A digital calliper was used to measure the cutting depth at the end of a cutting point. Furthermore, because the cutting depth differed at the start and end of the cut area, this difference in cutting depth was also compared.

Figure 2 shows a schematic of the difference in cutting depth. As shown in Figure 1, cutting with a laser requires a straight line to move the laser beam. When moving the beam, the speed, power, and gas pressure of the assist gas are maintained at a set level. However, the measured cutting depths differed at the start (1) and end (2) of the laser cut area, with a smaller cutting depth at the start (we refer to this difference as the cutting difference), as shown in Figure 2. The cutting difference can be calculated as follows:

$$
\mathrm{CD}=\mathrm{d}_{2}-\mathrm{d}_{1}
$$

CD: Cutting difference

$\mathrm{d}_{1}$ : Cutting depth at the start of cutting

$\mathrm{d}_{2}$ : Cutting depth at the end of cutting

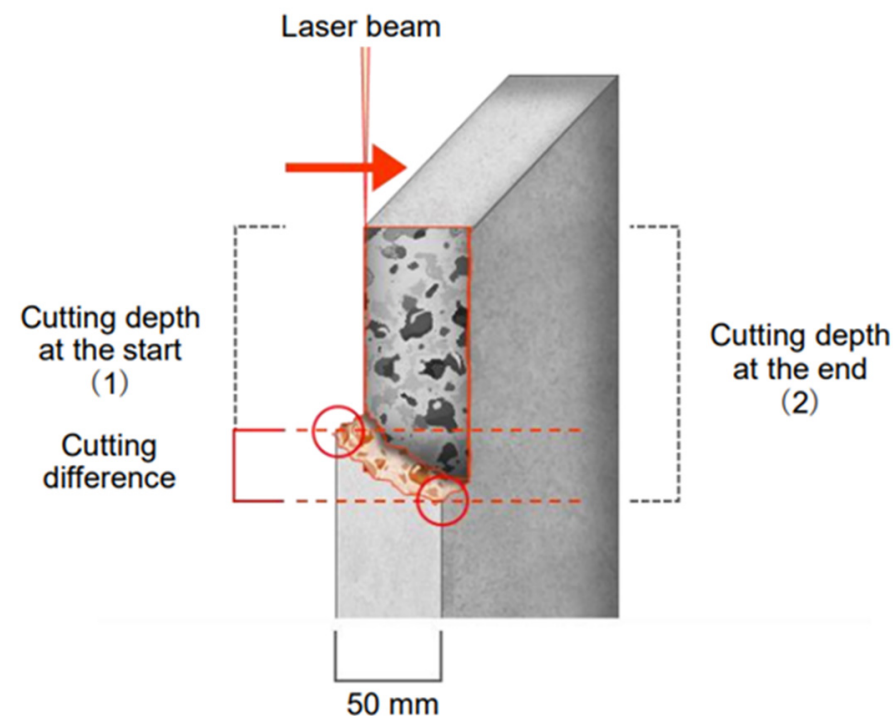

Figure 2. Schematic of the cutting difference.

2.4.2. Measuring the Presence of Vitrification, Cracking, etc.

Visual observation and a digital microscope (Keyence VHX-5000) were used to confirm the presence or absence of vitrification, cracking, etc. The vitrified portions were also observed over time. 


\section{Experimental Results and Discussion}

\subsection{Comparison of Laser Power}

Figures 3 and 4 show the relationship between cutting speed and depth (end of cutting) at different powers and concrete strengths, respectively.

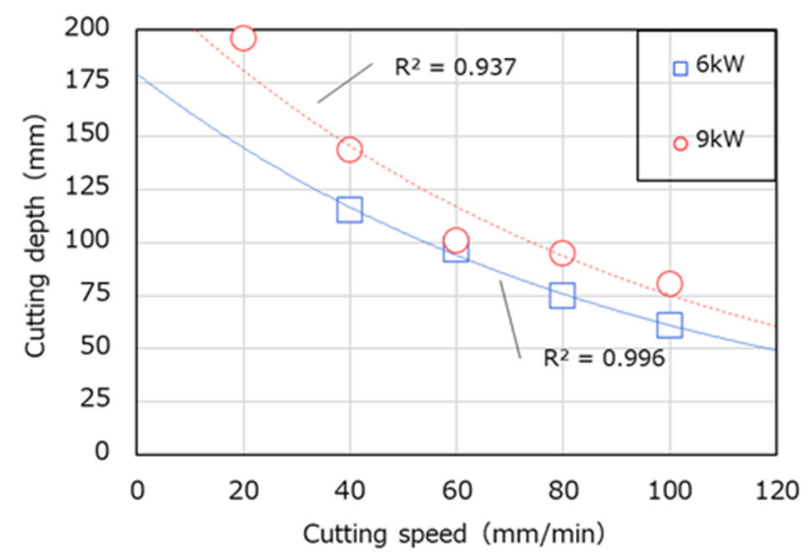

Figure 3. Relationship between the cutting speed and cutting depth for the two laser powers (compressive strength $20 \mathrm{~N} / \mathrm{mm}^{2}$ ).

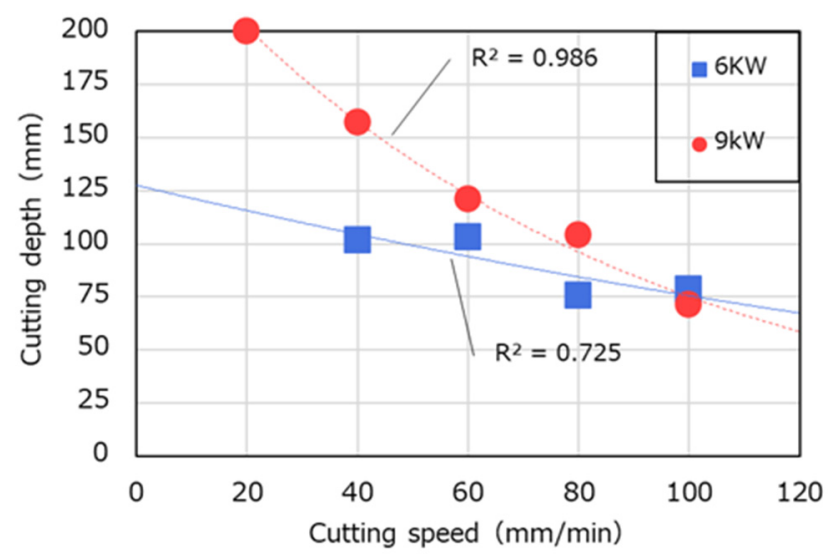

Figure 4. Relationship between the cutting speed and cutting depth for the two laser powers (compressive strength $130 \mathrm{~N} / \mathrm{mm}^{2}$ ).

When concrete strength was $20 \mathrm{~N} / \mathrm{mm}^{2}$, and laser powers were 6 and $9 \mathrm{~kW}$, the cutting depth increased as the cutting speed decreased or the power increased.

The laser was able to cut to a depth of $116 \mathrm{~mm}$ when the power and cutting speed were $6 \mathrm{~kW}$ and $40 \mathrm{~mm} / \mathrm{min}$, respectively. In addition, when the power and cutting speed were $9 \mathrm{~kW}$ and $40 \mathrm{~mm} / \mathrm{min}$, respectively, the laser was able to cut to a depth of approximately $150 \mathrm{~mm}$. Therefore, the average cutting depth for the $9 \mathrm{~kW}$ laser power was 1.28 times that of the $6 \mathrm{~kW}$ laser power. The correlation coefficient between the cutting speed and cutting depth at a concrete strength of $20 \mathrm{~N}$ was greater than 0.9 .

In the case of concrete with a strength of $130 \mathrm{~N} / \mathrm{mm}^{2}$ and laser powers of 6 and $9 \mathrm{~kW}$, the slower the cutting speed, the greater the cutting depth was. In the case of the $6 \mathrm{~kW}$ laser power, the correlation coefficient between the cutting speed and cutting depth was 0.7, which was lower than that of the $9 \mathrm{~kW}$ laser power. When the cutting speed was $100 \mathrm{~mm} / \mathrm{min}$, the cutting effectiveness values of different powers were identical. When the cutting speed was less than $100 \mathrm{~mm} / \mathrm{min}$, the cutting effectiveness differed for different power values, indicating that the heat accumulation changed with concrete strength. Therefore, cutting high-strength concrete requires a high-power laser.

Consequently, the greater the concrete strength, the higher its denser is, and the thermal conductivity it becomes [17]. Hence, even when the laser is irradiated at the same 
power and cutting speed, concrete with a strength of $130 \mathrm{~N} / \mathrm{mm}^{2}$ is highly susceptible to heat during irradiation. However, owing to its denser nature, a larger amount of heat is required to melt concrete. Moreover, concrete with a strength of $20 \mathrm{~N} / \mathrm{mm}^{2}$ has a greater porosity. Therefore, it requires less heat to melt. Consequently, the lower the concrete strength is, the greater the cutting depth is. The results of other studies are similar to this ordinary concrete result. As a result, it was found that the different concrete affects the cutting speed or cutting depth.

\subsection{Comparison of Concrete Strength}

Figures 5 and 6 show the relationship between cutting depth (end of cutting) of a strength of $20 \mathrm{~N} / \mathrm{mm}^{2}$ and cutting depth of a strength of $130 \mathrm{~N} / \mathrm{mm}^{2}$ for the two laser powers.

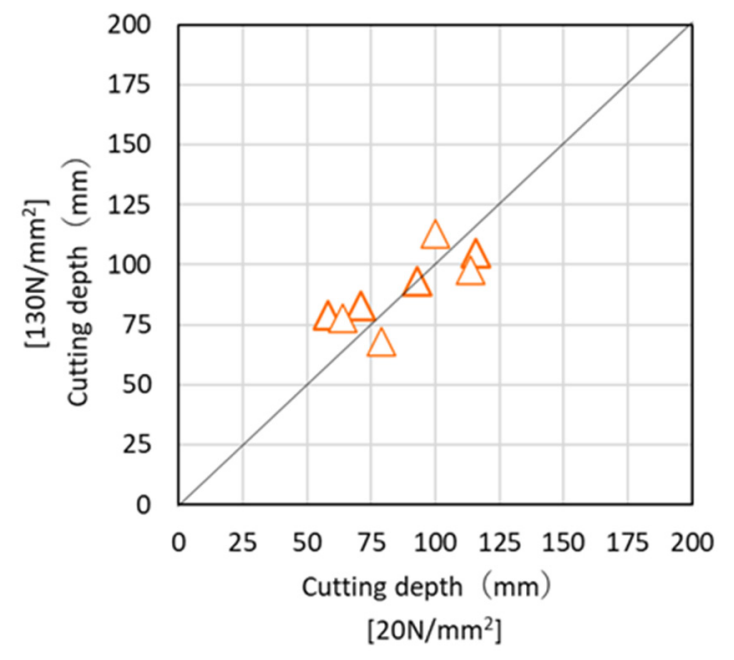

Figure 5. Correlation between cutting depth and concrete strength (laser $6 \mathrm{~kW}$ ).

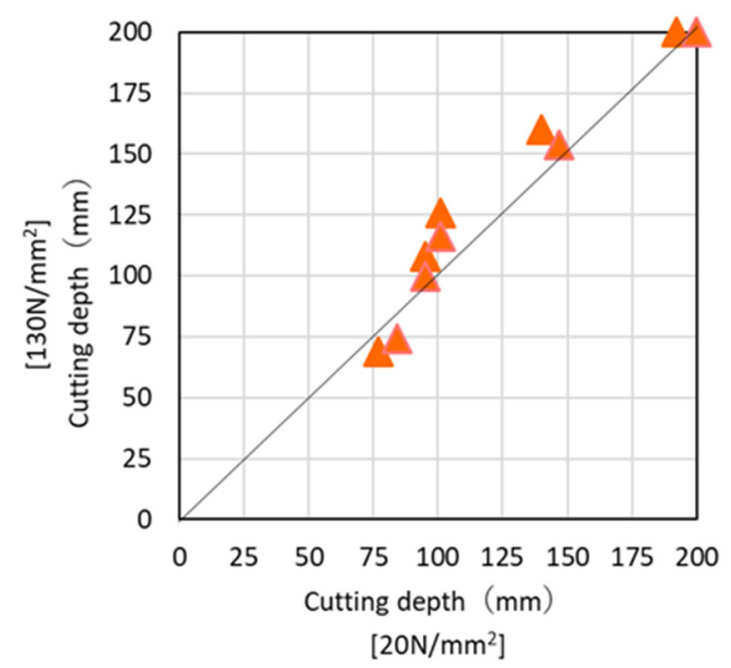

Figure 6. Correlation between cutting depth and concrete strength (laser $9 \mathrm{~kW}$ ).

When the laser power was $6 \mathrm{~kW}$, the cutting depth remained almost the same for concretes with different strengths. In this experiment, the cutting depth ranged between 50 and $120 \mathrm{~mm}$.

In the case of the $9 \mathrm{~kW}$ laser power, the cutting depth was between 75 and $200 \mathrm{~mm}$, which was larger than that of the $6 \mathrm{~kW}$ laser power. Hence, the heat effect on the specimen was larger with the $9 \mathrm{~kW}$ laser power, and the cutting depth was approximately the same, regardless of the concrete strength. 
This phenomenon caused the concrete with a strength of $130 \mathrm{~N} / \mathrm{mm}^{2}$ to be completely cut, and in the case of the concrete with a strength of $20 \mathrm{~N} / \mathrm{mm}^{2}$, the molten material re-adhered after cutting.

This result was due to the thermal effects of concrete strengths mentioned in Section 3.1. High-strength concrete has a high material separation resistance and a high viscosity [18]. In addition, owing to its higher density, the cutting was likely due to the heat explosion and similar effects.

\subsection{Differences in Cutting Surfaces Due to Different Concrete Strengths}

Figure 7 shows the surface of the cut part of the specimens for each concrete strength after laser cutting. In the photo, the cutting depths are approximately $118 \mathrm{~mm}$ and $126 \mathrm{~mm}$ for the specimens with strengths of $20 \mathrm{~N} / \mathrm{mm}^{2}$ and $130 \mathrm{~N} / \mathrm{mm}^{2}$, respectively.

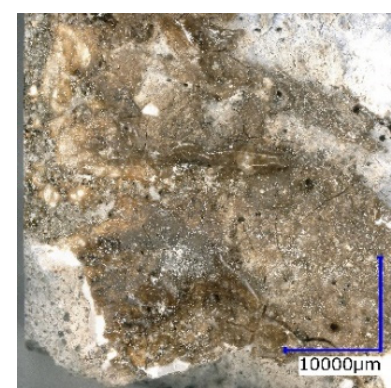

$20 \mathrm{~N} / \mathrm{mm}^{2}$

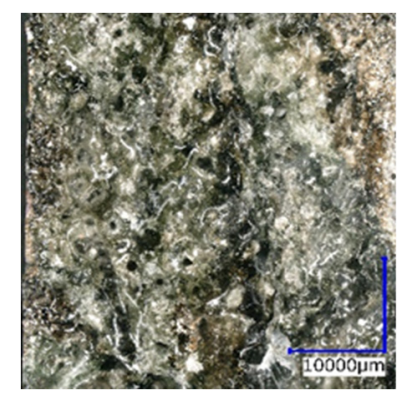

$130 \mathrm{~N} / \mathrm{mm}^{2}$

Figure 7. Cut surface after irradiation.

While observing the cross-sections, the specimen with a strength of $20 \mathrm{~N} / \mathrm{mm}^{2}$ showed dull vitrification. Contrastingly, the specimen with a strength of $130 \mathrm{~N} / \mathrm{mm}^{2}$ showed glossy vitrification. This is because when the concrete strength is low, the impact of the laser is channelled in the depth direction, whereas when the concrete strength is high, heat tends to accumulate locally, owing to the higher thermal conductivity and density $[19,20]$.

\subsection{Difference in Cutting Depth}

Figure 8 shows the cutting depth at the start and end points of the cutting distance. This graph indicates that the cutting depth at the cutting start and end points was the same until a cutting distance of approximately $20 \mathrm{~mm}$ was reached. At a cutting distance of 20-35 mm, the cutting difference increased. When the cutting distance was in the range of $35-50 \mathrm{~mm}$, the cutting difference was almost the same. This phenomenon indicates that the effect of the concrete material on the concrete cutting differs depending on the cutting distance. This point has not been discussed before. It is important to understand this phenomenon in the case of cutting concrete over $80 \mathrm{~mm}$ using a high-power laser.

Figure 9 shows a schematic diagram of the cutting difference regarding the heat influence by laser cutting distance. This figure shows the surface condition of the cutting start point because of the difference in cutting distance. The upper part shows the concrete inside the model according to each cutting distance. The lower row shows the photograph of the cutting start point for each cutting distance. The $50 \mathrm{~mm}$ point shows the cutting start point (c.1) and cutting end point (c.2) only. This model describes the situation in Figure 8. 


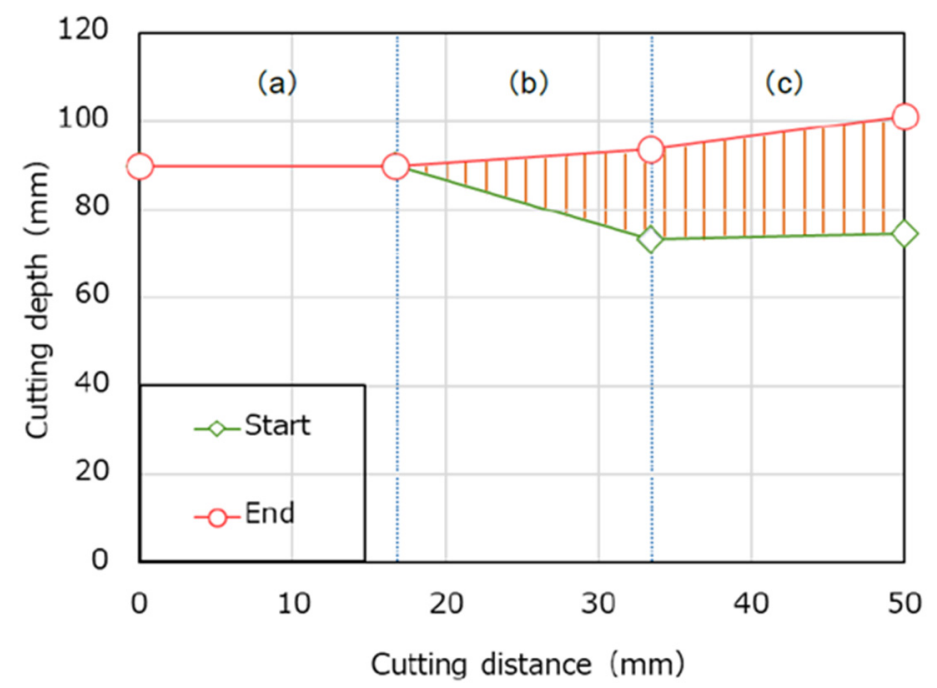

Figure 8. Result in the cutting difference due to difference in the cutting distance (laser: $9 \mathrm{~kW}$; speed: $60 \mathrm{~mm} / \mathrm{min}$; strength: $20 \mathrm{~N} / \mathrm{mm}^{2}$ ).

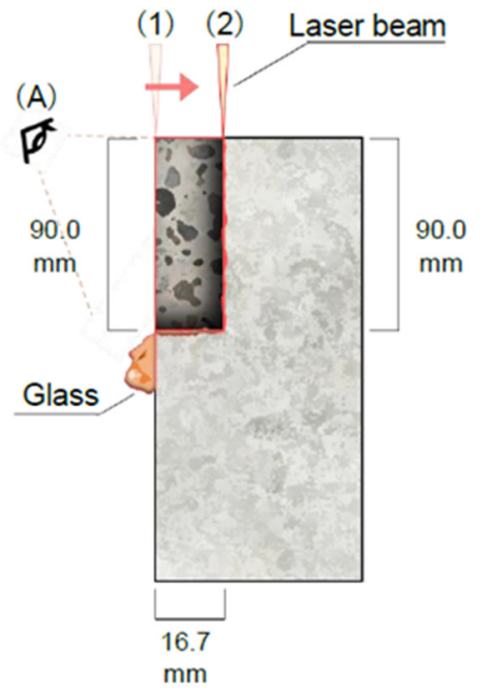

(a)

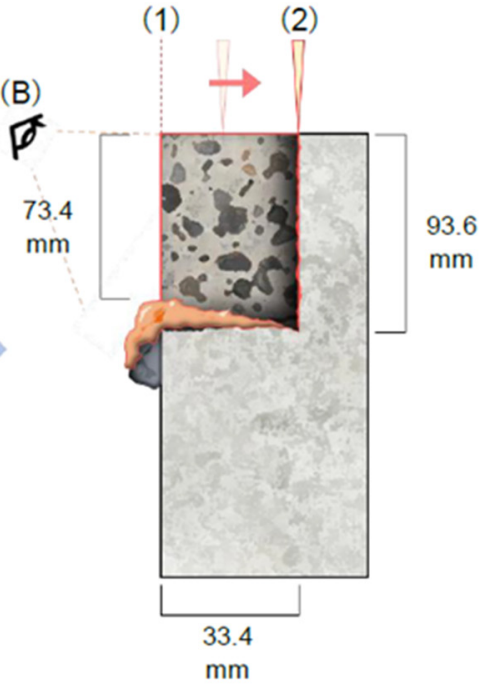

(b)

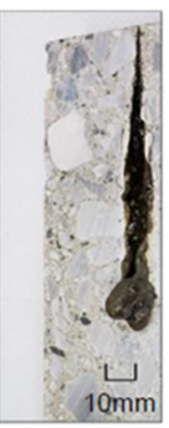

(A)

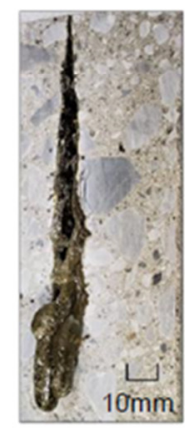

(B)

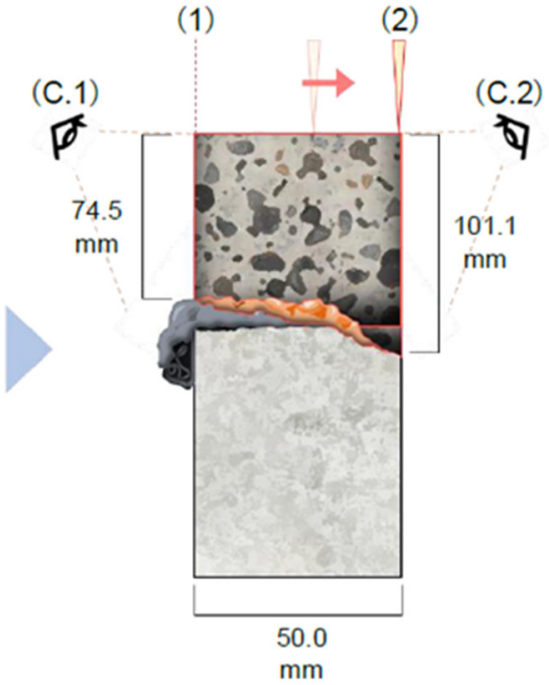

(c)

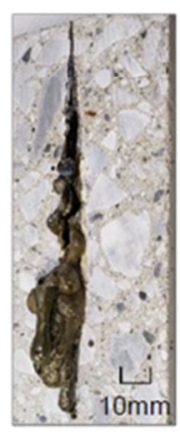

(C.1)

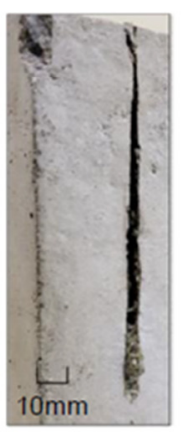

(C.2)

Figure 9. Schematic of the cutting difference owing to heat influence (laser: $9 \mathrm{~kW}$; speed: $60 \mathrm{~mm} / \mathrm{min}$; strength: $20 \mathrm{~N} / \mathrm{mm}^{2}$ ). 
The reason for this is that the thermal effect of the laser during cutting melts the cement and aggregates materials contained in the concrete, which are ejected at the beginning of the laser cutting, as shown in Figure 9. As the laser moves across the concrete, the material melted by the heat at the cutting site accumulates and fills the area where the cutting begins, creating the difference in cutting. Hence, it was confirmed that when the cutting was deep and the cutting distance was long, glass and the like were accumulated inside the concrete. Thus, the glass must be removed.

Furthermore, as shown in Figure 10, the heat accumulation (the amount of heat received) differed at the start and end points of cutting. For example, at the laser power of $6 \mathrm{~kW}$ and cutting speed of $20 \mathrm{~mm} / \mathrm{min}$, the specimen received $6 \mathrm{~kJ}$ of heat immediately after irradiation and $900 \mathrm{~kJ}$ of heat at the end. The higher the amount of heat was, the higher the temperature of the specimen was, indicating why the specimen was relatively hot at the end of the cutting. As the amount of heat increased, the heat effects and the amount of glass increased, generating a greater cutting depth.

(1) (2)

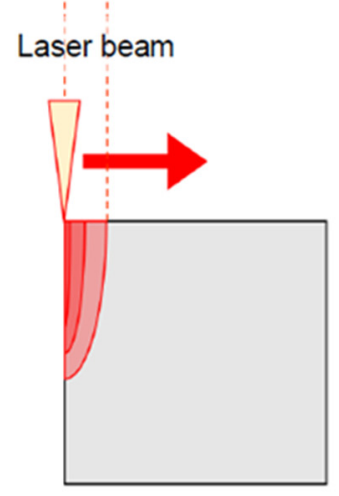

(a)

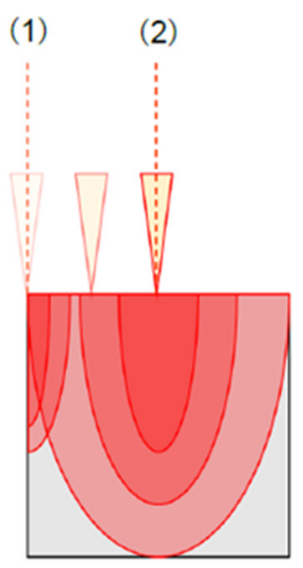

(b)

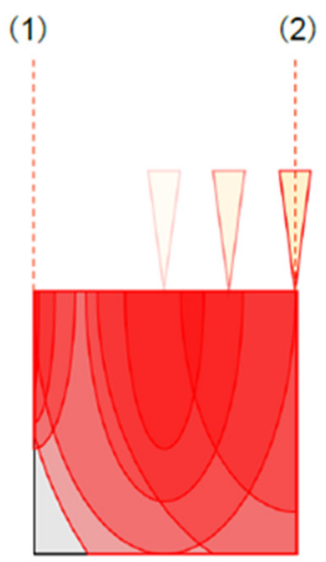

Heat affected zone

(c)

Figure 10. Schematic of thermal influence due to irradiation position.

\subsection{Cutting Effectiveness of the $\mathrm{CO}_{2}$ and Fibre Lasers}

Figure 11 shows the cutting depths of the $\mathrm{CO}_{2}$ and fibre lasers when the laser power was $9 \mathrm{~kW}$. The cutting depth of the $\mathrm{CO}_{2}$ laser was approximately $20 \mathrm{~mm}$ greater than that of the fibre laser at the cutting speed of $20 \mathrm{~mm} / \mathrm{min}$. This is due to differences in focal length, power density, assist gas flow rate, and similar parameters caused by differences in the laser oscillator and irradiation conditions. However, at the cutting speed of $50 \mathrm{~mm} / \mathrm{min}$, an identical cutting depth was obtained. Although $\mathrm{CO}_{2}$ laser data were not available, the results in the graph show that the cutting depths of the $\mathrm{CO}_{2}$ and fibre lasers were reversed or approximately the same at cutting speeds greater than $50 \mathrm{~mm} / \mathrm{min}$. Thus, both the $\mathrm{CO}_{2}$ and fibre lasers were roughly equivalent in terms of their cutting effectiveness in concretes at high speeds. However, the $\mathrm{CO}_{2}$ laser resulted in deeper cutting depths at slower speeds. 


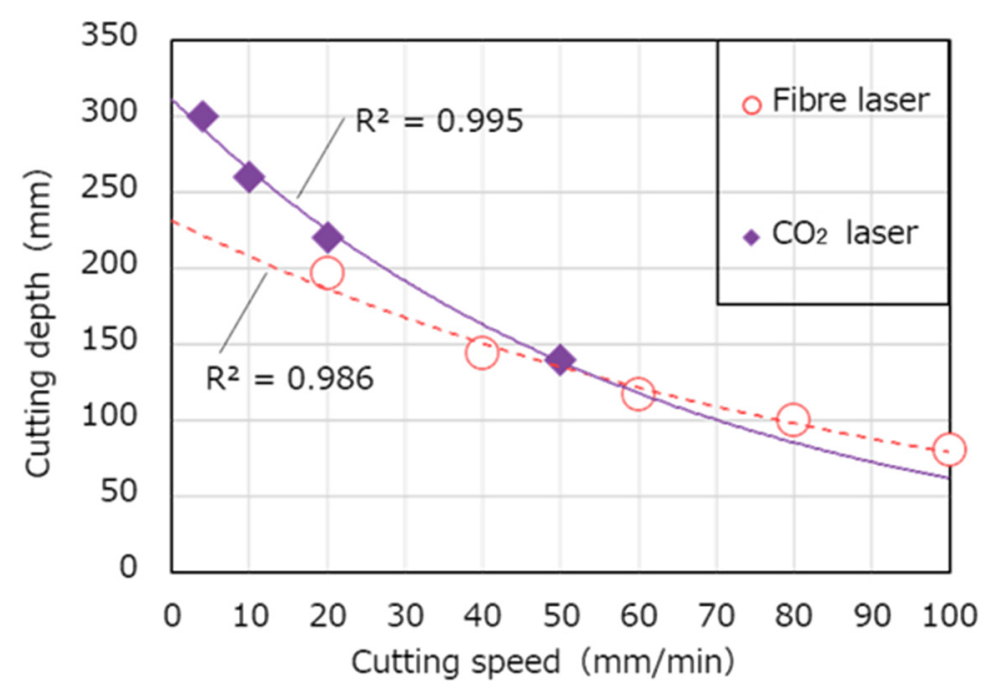

Figure 11. Cutting depth curves of the $\mathrm{CO}_{2}$ and fibre lasers (laser $9 \mathrm{~kW}$ ).

\section{Conclusions}

In this study, to compare two different concrete strengths for cutting to a depth of $200 \mathrm{~mm}$ thick concrete, the laser conditions were changed and the surface conditions of cutting were observed. This study confirmed that concrete cutting by a high-power fibre laser, which can be brought to construction sites, could be used where noise and dust are major problems. The main conclusions of this study are as follows:

1. At concrete strengths of $20 \mathrm{~N} / \mathrm{mm}^{2}$, the trend of cutting depth was the same even if the laser output was different.

2. At concrete strengths of $130 \mathrm{~N} / \mathrm{mm}^{2}$, the same cutting depth was indicated when the speed was $100 \mathrm{~mm}$, even if the laser output was different. However, when the speed decreased, the difference in laser output greatly affected the difference in cutting depth.

3. Cutting to a depth of $200 \mathrm{~mm}$ or more required a laser power of $9 \mathrm{~kW}$ and a cutting speed of $20 \mathrm{~mm} / \mathrm{min}$.

4. Regardless of the concrete strength, the concrete melted and vitrified if the heat effect became large.

5. In laser cutting, the cutting depths at the start and end points of cutting differed depending on the cutting method.

6. The $\mathrm{CO}_{2}$ and fibre lasers were roughly equivalent in terms of their cutting effectiveness in different concretes. However, the same cutting depth was indicated when the speed was $50 \mathrm{~mm}$. Furthermore, the $\mathrm{CO}_{2}$ laser resulted in deeper cutting depths at slow speeds than those of the fibre laser.

Author Contributions: All authors contributed equally to the various aspects of this study. Both authors have read and agreed to the published version of this manuscript.

Funding: This research received no external funding.

Acknowledgments: The authors gratefully acknowledge Kanamoto Corporation, ITO shokai, and some other laser companies for their helpful suggestions.

Conflicts of Interest: The authors declare no conflict of interest.

\section{References}

1. Kasai, Y. New dismantling method. Concr. J. 1973, 11, 39-48.

2. Kasai, Y. History of concrete technology 4th Transition of demolition method. Concr. J. 1992, 30, 87-91.

3. Kawashima, T.; Takagi, M. Dismantling method using a diamond wire saw. Concr. J. 1991, 29, 35-39.

4. Yanagida, K. Reinforced concrete (RC) building demolition method (3) Low noise demolition method. Concr. J. 2016, 54, 398-402. 
5. Yuasa, N. Reinforced concrete (RC) building demolition method (1) History of reinforced concrete demolition method. Concr. J. 2016, 54, 189-194.

6. Kitani, Y. High Power Laser Welding in Vacuum. J. JWS 2020, 89, 51-55. [CrossRef]

7. The Laser Society of Japan. Chapter 47 on Laser Applications; The Optronics Co., Ltd.: Tokyo, Japan, 1998; pp. 117-132.

8. Nagai, K.; Beckemper, S.; Poprawe, R. Laser Drilling of Holes in Different Kinds of Concrete. Civ. Eng. J. 2018, 4, 766-775. [CrossRef]

9. Sugita, K.; Mori, M.; Fujioka, T. Application of CO, Laser to Concrete Cutting. Concr. J. 1986, 24, 13-22. [CrossRef]

10. Yoshizawa, H.; Wignarajah, S.; Saito, H. Study on laser cutting of concrete. Trans. Japan Weld. Soc. 1989, $20,31-36$.

11. Nguyen, P. Experimental characterization of concrete removal by high-power quasi-continuous-wave fiber laser irradiation. $J$. Laser Appl. 2017, 29, 041501.

12. Lee, D.; Seo, Y.; Pyo, S. Effect of Laser Speed on Cutting Characteristics of Cement-Based Materials. Materials 2018, 11, 1055. [CrossRef] [PubMed]

13. Kutsumizu, A.; Tomura, H.; Wakizaka, T.; Hishikawa, K.; Moriya, M. Experimental study on concrete cutting bu $\mathrm{CO}_{2}$ laser beam. J. Struct. Constr. Eng. AIJ 1994, 464, 43-52. [CrossRef]

14. Nagai, K.; Sato, M.; Hattori, H.; Kinugasa, M. Rock excavation with laser. In High-Power Lasers in Civil Engineering and Architecture; SPIE-The International Society for Optical Engineering: Osaka, Japan, 2000; Volume 3887, pp. 277-286.

15. Wignarajah, S.; Nagai, K. Between a rock and a hard place. Ind. Laser Solut. Mag. 2005, 20, 8-12.

16. Nagai, K. Laser processing for construction site. Laser Inst. 2010, 39, 744-748.

17. Seo, T.Y.; Lee, D.; Pyo, S. High-Power Fiber Laser Cutting for 50-mm-Thick Cement-Based Materials. Materials 2020, $13,1113$. [CrossRef] [PubMed]

18. Saito, H. Optical Measurements in Experimental Mechanics; The Optical Society of Japan: Japan, 1965; pp. 3-10.

19. Li, Z.; Li, Q. Relationship between Compressive Strength and Thermal Conductivity of Concrete; Japan Concrete Institute: Tokyo, Japan, 2014; Volume 36, pp. 2050-2055.

20. Research Institute on Building Cost. Survey Report of "High-Strength Concrete"; New Technology Survey Report in Japan; Research Institute on Building Cost: Japan, 2010; pp. 80-85. 